\title{
Chemical synthesis of nanosized oxides
}

\author{
P PRAMANIK \\ Department of Chemistry, Indian Institute of Technology, Kharagpur 721302 , India
}

\begin{abstract}
Fine powder of single and binary mixed oxides can be produced by decomposition of the respective metal nitrates and polyvinyl alcohol (PVA) or, a mixture of PVA and polyacrylic acids. These mixtures, after spray drying, yjeld a brown fluffy mass, which is spontaneously combustible and the heat liberated is sufficient for the crystallization of the desired oxide phase. The rate of combustion controls the growth of the particles. This can be manifested by combustion of the mixture in controlled atmosphere. The nanoparticles of the oxide system studied are: spinels $\left[\mathrm{MFe}_{2} \mathrm{O}_{4}\right.$ where $\left.\mathrm{M}=\mathrm{Ni}(\mathrm{II}), \mathrm{Co}(\mathrm{II}), \mathrm{Zn}(\mathrm{II}), \mathrm{Mg}(\mathrm{II})\right]$; orthoferrites $\left[\mathrm{MFeO}_{3}\right.$ where $\mathrm{M}=\mathrm{Gd}(\mathrm{III}), \mathrm{Sm}$ (III)]; $\mathrm{LaAlO}_{3}, \mathrm{NdGaO}_{3}, \mathrm{CaO} / \mathrm{MgO} / \mathrm{Y}_{2} \mathrm{O}_{3}$ stabilized zirconia $\left(\mathrm{ZrO}_{2}\right)$; lead zirconate titanate $(\mathrm{PZT})$, lanthanum modified lead zirconate titanate (PLZT) and $\mathrm{BaTiO}_{3}$.
\end{abstract}

Keywords. Nanoparticles; chemical method; spinel: garnet; orthoferrites; PLZT; PZT.

\section{Introduction}

Research in the field of fine-grain ceramic mixed-oxide systems have gained immense importance because of their potential application in many areas of technology (Chirino and Sproule 1980; Slick 1980; Mitijevic 1989; Ozaki 1989). The conventional ceramic method for the preparation of powders of mixed-oxide systems involves high temperatures and thus sinters the final product, resulting in the loss of the fine particle nature. In recent years, a variety of non-conventional techniques (Roy 1960; Marcilly et al 1970; Sato et al 1971; Anderton and Sale 1979; Johnson Jr. 1981; Das 1981; Pathak and Pramanik 1993) have been used to prepare fine particle systems. These include spray-drying, freeze-drying, co-precipitation, sol-gel and hydrothermal oxidation/decomposition processes. In this paper we report a simple, cost effective and versatile route for the preparation of any desired mixed-oxide system at fairly low temperatures. The process involves thermal dehydration of the homogeneous aqueous solution of metal nitrates and polyvinyl alcohol (PVA). Pyrolysis of this organic based homogeneous mixture (which may be termed as the 'precursor') results in the desired oxide system. The present study deals with the preparation of a variety of mixed-oxide systems such as: spinels $\left[\mathrm{MFe}_{2} \mathrm{O}_{4}\right.$ where $\left.\mathrm{M}=\mathrm{Ni}(\mathrm{II}), \mathrm{Co}(\mathrm{II}), \mathrm{Zn}(\mathrm{II}), \mathrm{Mg}(\mathrm{II})\right]$; orthoferrites $\left[\mathrm{MFeO}_{3}\right.$ where $\left.\mathrm{M}=\mathrm{Gd}(\mathrm{III}), \mathrm{Sm}(\mathrm{III})\right] ; \mathrm{LaAlO}_{3}, \mathrm{NdGaO}_{3}, \mathrm{NdGaO}_{3}, \mathrm{CaO} /$ $\mathrm{MgO} / \mathrm{Y}_{2} \mathrm{O}_{3}$ stabilized zirconia $\left(\mathrm{ZrO}_{2}\right)$; lead zirconate titanate (PZT), lanthanum modified lead zirconate titanate (PLZT) and $\mathrm{BaTiO}_{3}$.

\section{Experimental}

To prepare the above mentioned oxide systems appropriate amounts of the desired metal nitrates are taken into aqueous solution. $10 \%(\mathrm{w} / \mathrm{v})$ aqueous solution of PVA (mol. wt. $=1,25,000)$ is then added to each of the mixed metal nitrate solutions so as to maintain a metal ion:vinyl alcohol monomer unit mole ratio of $1: 2$. The PVA helps the homogeneous distribution of the metal ions in its polymeric network structure and 


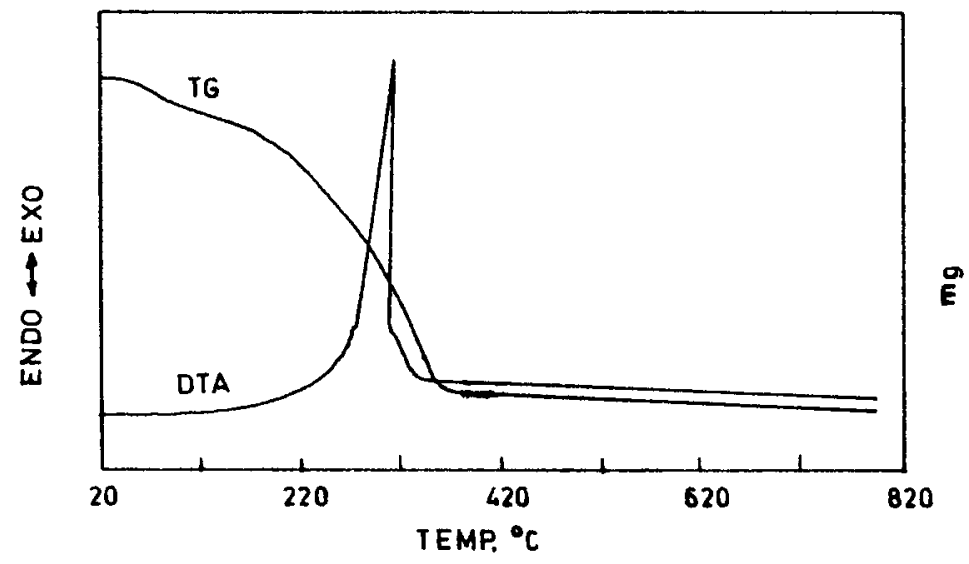

Figure 1. TG/DTA curves of $\mathrm{NiFe}_{2} \mathrm{O}_{4}$ precursor powders.

inhibits their segregation/precipitation from the solution. The resulting viscous mixture of PVA metal nitrates is spray dried between $130^{\circ} \mathrm{C}$ to $150^{\circ} \mathrm{C}$ to obtain a fluffy powder.

When the volume of the solution of mixed metal nitrates and PVA is reduced by evaporation, the nitrate ions provide an in situ oxidizing environment for the decomposition of the PVA. When complete dehydration occurs the nitrates themselves get decomposed with the evolution of brown fumes of nitrogen dioxide, leaving behind a voluminous organic based fluffy black powder (i.e. the precursor powder). Pyrolysis of these powders at various temperatures gives rise to the desired mixed-oxide phase. These powders on controlled oxidation result in nanocrystallites of the desired mixed oxide phase. The size of the nanocrystals can be controlled by varying the calcination time and temperature of the respective precursor powders.

\section{Results and discussion}

The choice of heat treatment temperatures for the respective systems is made on the basis of their thermo gravimetry (TG) and differential thermal analysis (DTA). TG and DTA of the precursor powders are done using Shimadzu DT-40 Thermal Analyser at the heating rate of $10^{\circ} \mathrm{C} / \mathrm{min}$ in air. The decomposition temperatures for all the systems under study are found to lie between $400^{\circ} \mathrm{C}$ and $500^{\circ} \mathrm{C}$ (figure 1). Thus the heat treatment of the ground precursor powders at their respective decomposition temperatures and beyond, results in the evolution of heat from the combustion of the residual carbonaceous material. This facilitates the reaction among the constituent metal ions and the formation of the desired oxide phase at a relatively low external temperature.

The powders obtained at varying stages of heat treatment are characterized by X-ray diffraction (XRD) using a Philips P.W. 1710 X-ray diffractometer with MoK $_{\alpha}$ radiation. The calcined precursor powders of the various systems within the temperature range $400-500^{\circ} \mathrm{C}$ reveal the characteristic XRD lines of the respective systems. The fine particle nature of the oxides is reflected from the X-ray line broadening. With the increase in the calcination temperatures there is a gradual increase in the peak intensities accompanied by the sharpening of the peaks (figure 2). This may be 


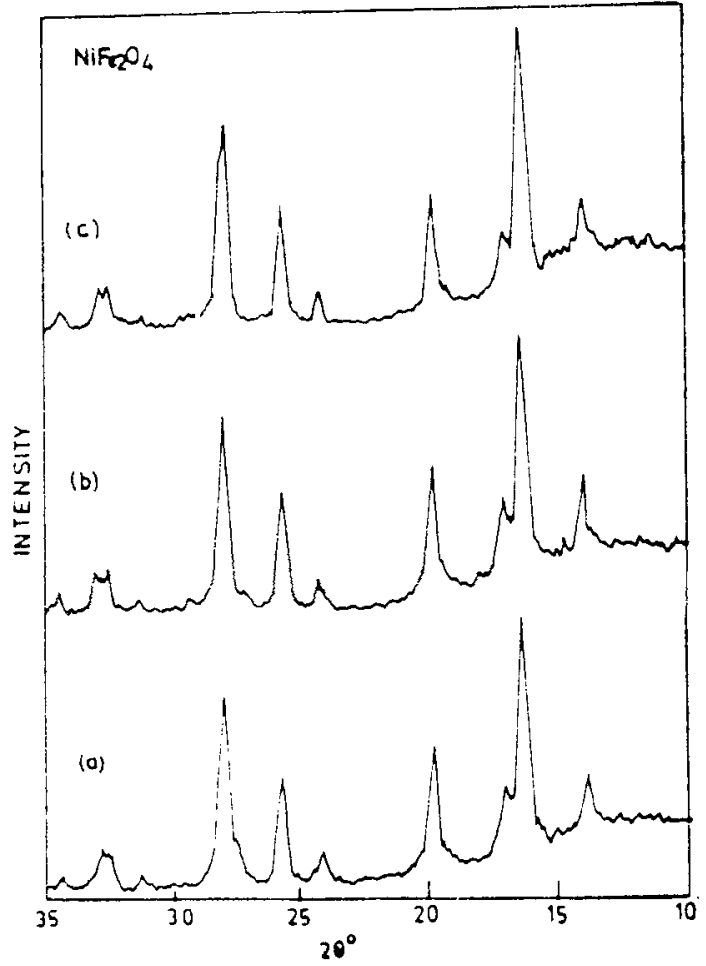

Figure 2. X-ray diffractograms of $\mathrm{NiFe}_{2} \mathrm{O}_{4}$ powder after calcination at (a) $450^{\circ} \mathrm{C}$. (b) $700 \mathrm{C}$ and (c) $900^{\circ} \mathrm{C}$.

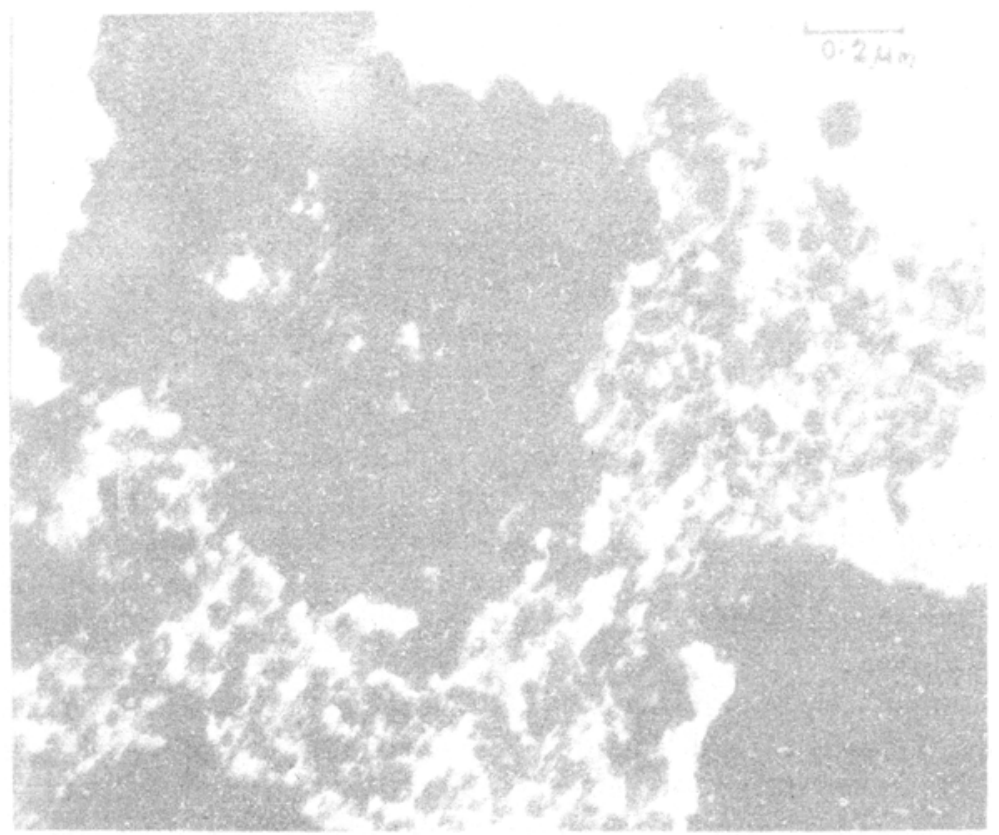

Figure 3. Transmission electron micrographs of $\mathrm{NiFe}_{2} \mathrm{O}_{4}$ powder after calcination at $450^{\circ} \mathrm{C}$ for $2 \mathrm{~h}$. 


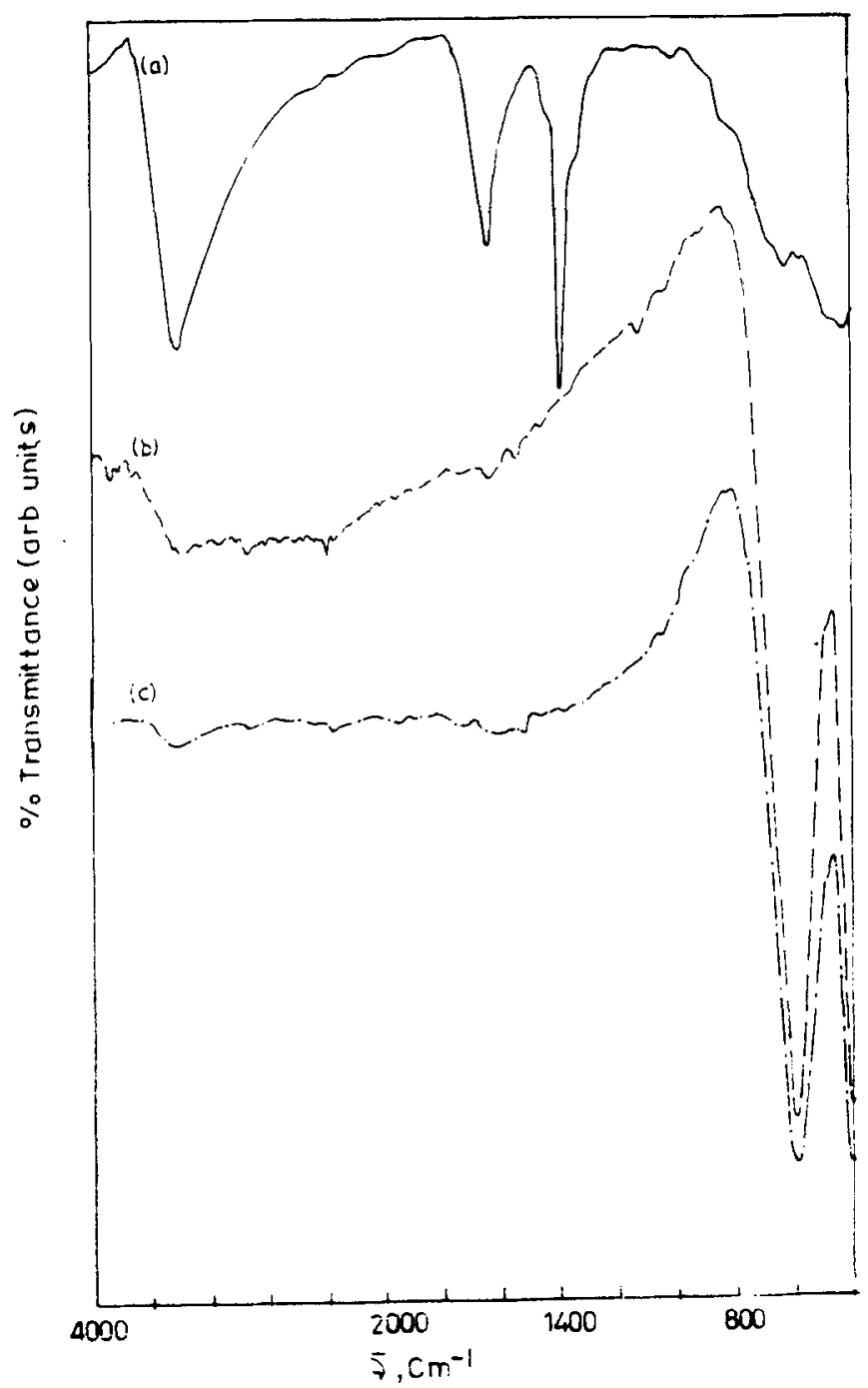

Figure 4. IR spectra of (a) precursor $\mathrm{NiFe}_{2} \mathrm{O}_{4}$ powder, (b) $\mathrm{NiFe}_{2} \mathrm{O}_{4}$ powder after calcination at $700^{\circ} \mathrm{C}$ and (c) $\mathrm{NiFe}_{2} \mathrm{O}_{4}$ powder after calcination at $900^{\circ} \mathrm{C}$.

attributed to gradual increase in the crystallite sizes with increase in calcination temperatures. The relative crystallite sizes are determined from the XRD line broadening using the Scherrers' equation (Klug and Alexander 1974).

The order of crystallite size ranges between $10 \mathrm{~nm}$ and $30 \mathrm{~nm}$ for ferrites; between $7 \mathrm{~nm}$ and $40 \mathrm{~nm}$ for stabilized zirconia systems and $8 \mathrm{~nm}$ and $30 \mathrm{~nm}$ for PZT, PLZT and $\mathrm{BaTiO}_{3}$ systems.

Transmission electron microscopy (TEM) studies for the oxide systems are done to measure the particle size distribution and morphology. TEM is done using a Philips EM-300 Electron Microscope. The particle size determined from the TEM (figure 3) is found to lie between $30 \mathrm{~nm}$ and $300 \mathrm{~nm}$ for all the systems under study.

The infrared spectroscopy (IR) studies of the precursor powders and the heat treatment samples are done using a Perkin Elmer 883 infrared spectrophotometer 
between $400 \mathrm{~cm}^{-1}$ and $2000 \mathrm{~cm}^{-1}$. Presence of some carbonaceous materials in all the precursor powders is evident from the IR spectra (figure 4) which depicts strong bands at $1638 \mathrm{~cm}^{-1}$ and $1382 \mathrm{~cm}^{-1}$ corresponding to carboxylate ions. This is also supported by the weight loss observed in the TG curve during decomposition of the metal oxide precursor powders (figure 1). These bands, corresponding to the carboxylate ions, disappear with the heat treatment of the precursor powder beyond their respective decomposition temperatures. This is also supported by the constant weight nature of TG curve beyond the decomposition temperature (figure 1). Thus, with the heat treated precursor powders only the IR band characteristic of the respective mixed oxide systems are observed.

\section{Conclusion}

In conclusion, the PVA mixed metal nitrate solution dehydration and decomposition is a versatile route for the preparation of any mixed-oxide system. The polymeric network structure of PVA inhibits segregation and precipitation of the constituent metal ions from the solution. Liberation of gases such as $\mathrm{NO}_{2}$ and $\mathrm{H}_{2} \mathrm{O}$ (water vapour) at the initial stage and $\mathrm{Co}, \mathrm{CO}_{2}$ and $\mathrm{H}_{2} \mathrm{O}$ at the later stages of the decomposition process, results in a highly porous/fluffy material which culminates the fine particle nature of the oxide systems. The evolution of gases helps not only the product to disintegrate but also to dissipate the heat of combustion, thus inhibiting sintering of the fine particles. Thus the low temperature $\left(400-500^{\circ} \mathrm{C}\right)$ exothermic decomposition of the carbonaceous material present in the precursor powders. reduces the processing temperature for the preparation of the fine particle of any mixed oxide system. The detailed studies of the various mixed oxides are in progress.

\section{Acknowledgement}

The author acknowledges the efforts and valuable contributions of his research scholars, Amita Pathak and S K Saha, towards the completion of this work.

\section{References}

Anderton D J and Sale E R 1979 Powder Metall. 2214

Chirino A M and Sproule R T 1980 Am. Cerum. Soc. Bull. 59604

Das B K 1981 in Preparation and characterization of materials (eds) J M Honig and C N R Rao (New York: Academic Press) p. 213

Johnson Jr. D W 1981 Am. Ceram. Soc. Bull. 60221

Klug H P and Alexander L E 1974 in X-ray diffraction procedure (New York: Wiley) p. 634

Marcilly C, Courty P and Delmon B 1970 J. Am. Ceram. Soc. 5356

Mitijevic E 1989 MRS Bull. XIV 19

Ozaki M 1989 MRS Bull. XIV 35

Pathak A and Pramanik P 1993 Mater. Manuf. Processes 8491

Roy R $1960 \mathrm{~J}$. Am. Ceram. Soc. $\mathbf{5 2} 344$

Sato T, Kurodo C, Saito M and Sugihara M 1971 in Ferrites, Proceedings of int. conference (eds) Y Hoshino. $\mathrm{S}$ Iida and M Sugimoto (Bathimore MD: University Park Press) p. 72

Slick P I 1980 in Ferromaynetic materials (eds) E P Wohlforth (New York: North Holland) Vol. 2 p. 189 